\title{
INCLUSÃO DO CAROÇO DE ALGODÃO EM RAÇÕES DE ALTO CONCENTRADO CONSTITUIIDO DE CO-PRODUTOS AGROINDUSTRIAIS SOBRE O DESEMPENHO ANIMAL EM TOURINHOS CONFINADOS
}

\author{
Luiz Juliano Valério Geron'1, Lúcia Maria Zeoula², Edson Júnior Heitor de Paula1, \\ Rodrigo Froede Ruppin ${ }^{3}$, Deivison Novaes Rodrigues ${ }^{3}$, Daiane Caroline Moura ${ }^{1}$ \\ 1 Universidade do Estado de Mato Grosso \\ 2 Universidade Estadual de Maringá \\ ${ }^{3}$ Universidade Federal do Mato Grosso
}

Endereço para correspondência: Luiz Juliano Valério Geron <ljgeron@yahoo.com.br

RESUMO: Objetivou-se avaliar a inclusão do caroço de algodão (0\%, 10\%, 20\% e $30 \%$ na MS da ração total) em rações contendo alto concentrado $85 \%$ (casca do grão de soja na proporção de 52,7 a $73,1 \%$ e farelo de soja de 0,0 a $10,2 \%$ na MS da ração total para os diferentes níveis de inclusão do caroço de algodão na dieta) e volumoso fixo a 15\% (bagaço de cana-de-açúcar hidrolisado) na alimentação de tourinhos terminados em confinamento sobre o ganho médio diário (GMD), conversão alimentar (CA) e eficiência alimentar (EA). Foram utilizados 32 tourinhos da raça Nelore, com idade média de 36 meses e com peso corporal (PC) inicial médio de $424 \square 25 \mathrm{~kg}$, por 90 dias, distribuídos em um delineamento experimental inteiramente casualizado. Os dados de GMD, CA e EA foram submetidos ANOVA e as diferenças obtidas foram testadas utilizando equação de regressão a $5 \%$ de probabilidade. A inclusão do caroço de algodão $(0 \%, 10 \%, 20 \%$ e $30 \%)$ em rações com alto concentrado não influenciou $(P>0,05)$ o GMD, a CA e a $E A$ de tourinhos terminados em confinamento. $O$ valor médio obtido para o GMD, CA e EA para os tourinhos alimentados com os diferentes teores de inclusão do caroço de algodão foi de $1,41 \mathrm{~kg} / \mathrm{dia}, 8,76 \mathrm{~kg}$ de MS/kg de ganho e $0,12 \mathrm{~kg}$ de ganho/kg de MS, respectivamente. Conclui-se que a inclusão de $30 \%$ de caroço de algodão em rações compostas com alto concentrado fornecidas à tourinhos terminados em confinamento não altera o ganho médio diário a conversão alimentar e a eficiência alimentar.

Palavras-chave: co-produto; ganho médio diário; gordura; proteína bruta.

\section{INCLUSION COTTONSEED IN DIETS WITH HIGH CONCENTRATE CONTAINING AGRO-INDUSTRIAL BY-PRODUCTS ON ANIMAL PERFORMANCE IN FEEDLOT BULLS}

\begin{abstract}
The objective was to evaluate the inclusion of cottonseed $(0 \%, 10 \%, 20 \%$ and $30 \%$ in DM) in high concentrate diets containing $85 \%$ (hulls soybean in the ratio from 52.7 to $73.1 \%$ ad soybean meal from 0.0 to $10.2 \%$ in total ration dry mater for different levels of inclusion of whole cottonseed in the diet) and roughage 15\% (bagasse sugarcane hydrolyzete) in the diets of bulls finished in feedlot on average daily gain (ADG), feed conversion (FC) and feed efficiency (FE). We used 32 bulls breed Nelore with mean age of 36 months and body weight (BW) initial mean of 424 $25 \mathrm{~kg} 90$ days, distributed in completely randomized design. Data of ADG, FC and FA are submitted ANOVA and the differences obtained were tested using the regression equation at $5 \%$ probability. The inclusion of cottonseed $(0 \%, 10 \%, 20 \%$ and $30 \%)$ in diets with high concentrate did not affect $(\mathrm{P}$ $>0.05)$ ADG, FC and FA of bulls finished in feedlot. The average value for ADG, FC and FA of bulls fed with different inclusion levels of cottonseed was $1.41 \mathrm{~kg} /$ day, 8.76 kilograms of DM/kg gain and $0.12 \mathrm{~kg}$ gain/kilogram of DM, respectively. Thus concluded that the inclusion of $30 \%$ of cottonseed in diets containing high concentrate, in the bulls finished in feedlot does not change the average daily gain, feed conversion and feed efficiency.
\end{abstract}

Key Words: by-product, average daily gain, fat, crude protein. 


\section{INTRODUÇÃO}

O estado de Mato Grosso (MT) utiliza apenas $30 \%$ do seu território para o desenvolvimento das atividades agroeconômicas. Mesmo com uma utilização restrita do seu território o MT é o maior produtor nacional de algodão e soja, além de ser grande produtor de milho, álcool e açúcar (ANUALPEC, 2007).

A região Centro-Oeste do Brasil concentra aproximadamente $35 \%$ do rebanho brasileiro de bovinos, sendo o estado de MT o maior detentor do rebanho, com aproximadamente 27 milhões de cabeças. Para que a produção bovina seja economicamente viável e competitiva é necessário, entre outros fatores, proporcionar ao animal condições de exteriorizar o máximo desempenho de suas potencialidades genéticas através do fornecimento de alimentação balanceada e de baixo custo visando alcançar as condições de peso para abate 0 mais precoce possível (Santello et al., 2006).

Normalmente na estação seca do ano, as plantas forrageiras apresentam desenvolvimento lento, com redução marcante nos teores de proteína e elevação nos teores de fibra pouco digestível e o consumo voluntário é reduzido (Peruchena, 1999), não atendo as exigências nutricionais dos bovinos em terminação.

Uma alternativa para a baixa produtividade e escassez de alimentos das pastagens é a terminação de bovinos em confinamento, que, no entanto, tem custo elevado, principalmente por causa do alto valor comercial dos alimentos concentrados tradicionais (protéicos e energéticos).

A agroindústria gera grandes quantidades de co-produtos provenientes do processo de industrialização dos grãos de cereais, oleaginosas e outras plantas de interasses comerciais. Como exemplo de co-produtos agroindustriais destaca- se o caroço de algodão, a casca do grão de soja, e o bagaço de cana-de-açúcar. O caroço de algodão é um co-produto rico em gordura, proteína e fibra efetiva (Valadares Filho et al., 2006a), a casca do grão de soja contêm carboidratos estruturais de fácil degradação ruminal (Zambom et al., 2001) e o bagaço de cana-de-açúcar é fonte de fibra fermentável no rúmen e geralmente apresenta baixo custo (Bulle et al., 1999). Desta maneira, o amido normalmente presente nos grãos de cereais, pode ser substituído por fibras altamente digestíveis, as quais podem ser a principal fonte de energia, o que modificaria o padrão de fermentação ruminal (Teixeira, 1998), mas não altera o desempenho animal. Além disso, a silagem de milho comumente utilizada como alimento volumoso nos confinamentos de bovinos, pode ser parcialmente substituída pelo bagaço de cana-de-açúcar (Henrique et al., 1999) sem prejudicar a performance animal.

O caroço de algodão compreende as seguintes porções casca, línter e plumas. A maior parte das plumas a indústria têxtil retira no processo de industrialização do algodão, restando desta forma, a fibra, composta pelo línter (celulose de alta degradabilidade) e sobras da pluma, casca e a amêndoa (Fernandes et al., 2002; Rogério et al., 2003).

O caroço de algodão é um coproduto da indústria têxtil muito utilizado na alimentação de ruminantes por apresentar alta concentração de óleo, proteína e fibra, o que permite a substituição de alimentos volumosos e concentrados sem prejudicar a fermentação ruminal. Poucos alimentos conseguem reunir estes nutrientes em altas concentrações e apresentar uma fibra de alta degradabilidade como o caroço de algodão (Ezequiel, 2001; Harvatine et al., 2002; Rogério et al., 2003 e Pesce, 2008). 
Inclusão do caroço de algodão em rações de alto concentrado constituído de co-produtos agroindustriais sobre o desempenho animal em tourinhos confinados.

A composição química do caroço de algodão com línter é de $23,0 \%$ de proteína bruta (PB), $20,0 \%$ de extrato etéreo (EE), 44,0\% de fibra em detergente neutro (FDN), 34,0\% de fibra em detergente ácido (FDA) e 96,0\% de nutrientes digestíveis totais (NDT), estas qualidades aliadas ao baixo custo, fazem deste co-produto um bom suplemento protéico e energético em áreas de produção de algodão (Coppock et al., 1987; NRC, 1989 e Pesce, 2008).

A casca do grão de soja é obtida da industrialização do grão da soja, a qual possui grande destaque no cenário nacional, em virtude da alta produção brasileira de soja, sendo que a casca representa 7 a $8 \%$ do peso do grão (Restle et al., 2004).

Por apresentar alto conteúdo de FDN, a casca do grão de soja foi estudada como opção para substituir a fração volumosa da dieta em bovinos de corte e ovinos (Tambara et al., 1995; Azevedo, 1998; Zambom, et al., 2001; e Morais et al., 2007). No entanto, resultados confirmaram a elevada digestibilidade da FDN presente na casca do grão de soja, a alta produção de ácidos graxos voláteis (AGV), devido à excelente fermentabilidade desta fração (Morais et al., 2007), além de apresentar benefícios sobre a digestão da fibra da dieta total e o pH ruminal (Ludden et al., 1995; Gomes, 1998, e Zambom et al., 2001) induzindo novos estudos sobre a utilização da casca do grão de soja como substituto dos grãos de cereais na fração concentrado da dieta.

Estudos realizados por Zambom et al. (2007) e Zambom et al. (2008) para avaliar os parâmetros digestivos, produção e qualidade do leite de cabras Saanen alimentadas com 0\%, 50\% e $100 \%$ de substituição do milho pela casca do grão de soja concluíram que a casca do grão de soja pode substituir $100 \%$ o grão de milho sem alterar $(P>$
0,05 ) a ingestão e digestibilidade dos nutrientes, a concentração de nitrogênio amoniacal, $\mathrm{pH}$ ruminal e a produção e qualidade físico-química do leite.

O bagaço da cana-de-açúcar hidrolisado é uma alternativa que pode ser utilizada na alimentação de animais ruminantes, principalmente na época da seca, como fonte de energia fermentável no rúmen. $O$ bagaço de cana-de-açúcar hidrolisado é um coproduto com alto teor de FDN aproximadamente $80 \%$ na MS, sendo este uma fonte de carboidratos estruturais (celulose e hemicelulose). Estes carboidratos estruturais são degradados no rúmen dos bovinos pelas bactérias celulolíticas, que produzem AGV (acético, butírico e propiônico) absorvidos na parede ruminal e metabolizados no tecido animal como fonte de energia, essencial para a produção animal (Van Soest, 1994).

A eficiente utilização dos alimentos pelos animais depende de um suprimento adequado de energia e proteína. A deficiência de energia retarda o crescimento, aumenta a idade à puberdade, reduz a fertilidade, diminui o ganho de peso e a produção de leite. Segundo Resende et al. (2001), a necessidade energética pode ser afetada pela idade, tamanho do corpo, crescimento, estado fisiológico e fatores do meio ambiente, tais como temperatura, umidade, intensidade solar e velocidade do vento.

A eficiência de utilização de fontes protéicas é fundamental para o crescimento dos microrganismos, uma vez que juntamente com a energia fermentável no rúmen, define a eficiência de síntese microbiana (Hoover e Stokes, 1991), o que resulta em melhor desempenho animal, quando existe uma aproximação na sincronização entre a disponibilidade de energia e proteína para o crescimento microbiano. 
Portanto, objetivou-se avaliar a inclusão de $0 \% ; 10 \% ; 20 \%$ e $30 \%$ de caroço de algodão em rações com alto concentrado ( $85 \%$ constituído de casca do grão de soja e farelo de soja) e volumoso ( $15 \%$ de bagaço de cana-deaçúcar hidrolisado) fornecido a tourinhos terminados em confinamento sobre o desempenho animal (ganho médio diário, conversão alimentar e eficiência alimentar).

\section{MATERIAL E MÉTODOS}

O estudo foi conduzido na fazenda Lagoa do Guaporé, localizada no Município de Pontes e Lacerda - MT, situada a $15^{\circ} 19^{\prime} 05^{\prime \prime}$ de latitude Sul e $59^{\circ} 13^{\prime} 26^{\prime \prime}$ de longitude Oeste e a uma altitude de 295 metros e no Laboratório de Análise de Alimentos e Nutrição Animal pertencente ao Departamento de Zootecnia da Universidade do Estado de Mato Grosso Campus Universitário de Pontes e Lacerda.

A instalação utilizada para a execução do estudo foi composta por 4 baias coletivas, cada baia possuía 140 $\mathrm{m}^{2}$ de área total, 8 metros lineares de cocho e um bebedouro de concreto para cada duas baias. As medidas preventivas para controle das parasitoses e doenças foram feitas de acordo com as recomendações normais para esta atividade.

Foram utilizados 32 tourinhos da raça Nelore, com idade média de 36 meses e com peso corporal (PC) inicial médio de $424 \pm 25 \mathrm{~kg}$, em um ensaio de desempenho animal em sistema de confinamento. Os animais foram identificados individualmente por brincos plásticos. Os tourinhos foram alojados ao acaso em baias coletivas com capacidade para oito tourinhos cada, e alimentados com dietas contendo quatro teores de caroço de algodão $(0 \% ; 10 \%$; $20 \%$ e $30 \%$ ) durante 90 dias. A inclusão do caroço de algodão nas dietas foi determinada pelo teor máximo de 7,0\% de extrato etéreo na ração total.

Os tourinhos passaram por um período de adaptação às dietas e ao manejo de 15 dias. Neste período, a ração foi fornecida gradualmente até atingir a estabilidade do consumo de matéria seca (MS), com uma sobra de aproximadamente $10 \%$ por dia.

Os tourinhos foram pesados antes da primeira refeição do dia (jejum de sólidos de 12 horas) para entrarem no período de adaptação. No período experimental foram efetuadas três pesagens, uma inicial e uma a cada 25 dias, sendo que antes de todas elas os tourinhos foram submetidos a um jejum sólido de 12 horas. Todas as pesagens foram realizadas por meio de balança eletrônica digital.

O processamento de hidrólise do bagaço de cana-de-açúcar in natura (BIN) foi realizado na fazenda Lagoa do Guaporé, onde foi adicionada a solução de cal microprocessada. Foi utilizada uma dosagem de $0,5 \%$ de cal ( $\mathrm{CaO}$ - cal virgem) para cada $100 \mathrm{~kg}$ do BIN diluídos em quatro litros de água para disponibilizar a formação do hidróxido de cálcio $\left(\mathrm{Ca} \quad(\mathrm{OH})_{2}\right)$ segundo recomendações de Oliveira et al. (2007).

A distribuição da solução de cal microprocessada foi realizada por meio de bomba manual de aspersão sobre uma camada de aproximadamente quinze centímetros de altura de bagaço de cana-de-açúcar in natura previamente espalhada sobre um piso cimentado em um galpão coberto, sendo realizada posteriormente a homogeneização do bagaço de canade-açúcar e em seguida providenciou 0 armazenado em um silo de superfície.

A composição química dos alimentos concentrados (caroço de algodão, o farelo de soja, a casca do grão de soja) e do volumoso (bagaço da cana-de-açúcar hidrolisado com cal microprocessada) utilizados na 
Inclusão do caroço de algodão em rações de alto concentrado constituído de co-produtos agroindustriais sobre o desempenho animal em tourinhos confinados.

confecção das rações experimentais está demonstrada na Tabela 1.

A composição percentual e química das rações experimentais está demonstrada na Tabela 2. As rações experimentais foram formuladas para apresentarem teores de $0 \% ; 10 \% ; 20 \%$ e $30 \%$ de inclusão do caroço de algodão e foram compostas de $15 \%$ de volumoso (bagaço de cana-de-açúcar hidrolisado) e $85 \%$ de concentrado (caroço de algodão, casca do grão de soja, farelo de soja). As proporções de cada alimento que constituíram as rações experimentais podem ser observadas na Tabela 2.

Tabela 1- Composição química dos alimentos.

\begin{tabular}{|c|c|c|c|c|c|c|c|c|c|}
\hline \multirow{2}{*}{$\begin{array}{l}\text { Aliment } \\
\text { o }\end{array}$} & \multicolumn{9}{|c|}{$\%$ na MS } \\
\hline & $\begin{array}{l}\text { MS } \\
(\%)\end{array}$ & $\mathrm{MO}$ & PB & $\mathrm{EE}$ & $\begin{array}{l}\text { FD } \\
\mathrm{N}\end{array}$ & MM & $\begin{array}{l}\mathrm{CH} \\
\mathrm{T}\end{array}$ & $\begin{array}{l}\mathrm{CN} \\
\mathrm{F}\end{array}$ & $\begin{array}{l}\mathrm{ND} \\
\mathrm{T}^{2}\end{array}$ \\
\hline $\begin{array}{l}\text { Bagaço } \\
\text { de } \\
\text { cana- } \\
\text { de- } \\
\text { açúcar } \\
\text { hidrolis } \\
\text { ado }\end{array}$ & $\begin{array}{l}54, \\
08\end{array}$ & $\begin{array}{l}95, \\
76\end{array}$ & $\begin{array}{l}1,6 \\
0\end{array}$ & $\begin{array}{l}1,4 \\
9\end{array}$ & $\begin{array}{l}88, \\
44\end{array}$ & $\begin{array}{l}4,2 \\
4\end{array}$ & $\begin{array}{l}92, \\
66\end{array}$ & $\begin{array}{l}8,3 \\
3\end{array}$ & $\begin{array}{l}43, \\
52\end{array}$ \\
\hline $\begin{array}{l}\text { Casca } \\
\text { do grão } \\
\text { de soja }\end{array}$ & $\begin{array}{l}90 \\
17\end{array}$ & $\begin{array}{l}95, \\
80\end{array}$ & $\begin{array}{l}10 . \\
92\end{array}$ & $\begin{array}{l}2,3 \\
7\end{array}$ & $\begin{array}{l}53, \\
34\end{array}$ & $\begin{array}{l}4,2 \\
0\end{array}$ & $\begin{array}{l}60 \\
07\end{array}$ & $\begin{array}{l}13 \\
23\end{array}$ & $\begin{array}{l}81, \\
92\end{array}$ \\
\hline $\begin{array}{l}\text { Caroço } \\
\text { de } \\
\text { algodã }\end{array}$ & $\begin{array}{l}90 \\
28\end{array}$ & $\begin{array}{l}96, \\
20\end{array}$ & $\begin{array}{l}19, \\
11\end{array}$ & $\begin{array}{l}17 \\
02\end{array}$ & $\begin{array}{l}69, \\
24\end{array}$ & $\begin{array}{l}3,8 \\
0\end{array}$ & $\begin{array}{l}82, \\
52\end{array}$ & $\begin{array}{l}6,4 \\
8\end{array}$ & $\begin{array}{l}68, \\
77\end{array}$ \\
\hline $\begin{array}{l}\text { Farelo } \\
\text { de Soja }\end{array}$ & $\begin{array}{l}88 \\
16\end{array}$ & $\begin{array}{l}93 \\
34\end{array}$ & $\begin{array}{l}49 \\
41\end{array}$ & $\begin{array}{l}1,5 \\
9\end{array}$ & $\begin{array}{l}20, \\
13\end{array}$ & $\begin{array}{l}6,6 \\
6\end{array}$ & $\begin{array}{l}42, \\
34\end{array}$ & $\begin{array}{l}26, \\
89\end{array}$ & $\begin{array}{l}81, \\
54\end{array}$ \\
\hline $\begin{array}{l}\text { Calcári } \\
0^{2}\end{array}$ & $\begin{array}{l}99, \\
27\end{array}$ & $\begin{array}{l}0,4 \\
6\end{array}$ & -- & -- & -- & $\begin{array}{l}97, \\
33\end{array}$ & -- & -- & -- \\
\hline Premix & $\begin{array}{l}99, \\
00\end{array}$ & $\begin{array}{l}1,0 \\
0\end{array}$ & -- & -- & -- & $\begin{array}{l}99, \\
00\end{array}$ & -- & -- & -- \\
\hline $\begin{array}{l}\text { Sal } \\
\text { branco } \\
2\end{array}$ & $\begin{array}{l}99, \\
07\end{array}$ & $\begin{array}{l}10, \\
71\end{array}$ & -- & -- & -- & $\begin{array}{l}89 \\
29\end{array}$ & -- & -- & -- \\
\hline
\end{tabular}

MS: matéria seca; MO: matéria orgânica; $\mathrm{PB}$ : proteína bruta; EE: extrato etéreo; FDN: fibra em detergente neutro; MM: matéria mineral; $\mathrm{CHT}$ : carboidratos totais, '(SNIFEEN et al., 1992), CNF: Carboidratos não fibrosos e NDT: nutrientes digestíveis totais, ${ }^{2}$ (adaptado: VALADARES FILHO et al., 2006b).

As rações foram balanceadas para apresentares teores semelhantes de energia (66\% de NDT) e proteína bruta $(12 \%)$ segundo Valadares Filho et al. (2006b), ou seja, rações isoprotéica e isoenergética (Tabela 2).

Os tourinhos receberam as dietas três vezes ao dia, as sete, doze e dezessete horas. Os alimentos foram pesados em balança digital com capacidade de $200 \mathrm{~kg}$, existente na fazenda Lagoa do Guaporé.

Durante a condução do período de avaliação experimental foram realizadas amostragens dos alimentos (bagaço da cana-de-açúcar hidrolisado, caroço de algodão, casca do grão de soja e farelo de soja) a cada três dias para posterior análise química dos nutrientes. As sobras de alimentos foram pesadas diariamente, antes da primeira alimentação da manhã, para determinação da quantidade de alimento recusado e estimativas de ingestão de nutrientes. A cada três dias foram coletadas aproximadamente 10\% do total das sobras para os diferentes teores de inclusão do caroço de algodão, os quais foram acondicionadas e congeladas para posterior análises químicas.

Tabela 2 - Composição percentual e química das rações experimentais.

\begin{tabular}{|c|c|c|c|c|}
\hline \multirow[t]{2}{*}{ Alimentos } & \multicolumn{4}{|c|}{$\begin{array}{lll}\begin{array}{l}\text { algodão } \\
\text { experimentais }\end{array} & \text { nas rações } \\
\end{array}$} \\
\hline & $0 \%$ & $10 \%$ & $20 \%$ & $30 \%$ \\
\hline \multicolumn{5}{|l|}{ Composição percentual } \\
\hline $\begin{array}{l}\text { Bagaço de cana-de- } \\
\text { açúcar hidrolisado }\end{array}$ & 15,0 & 15,0 & 15,0 & 15,0 \\
\hline Casca do grão de soja & 73,1 & 66,7 & 59,9 & 52,7 \\
\hline Caroço de algodão & 0,0 & 10,2 & 20,4 & 30,6 \\
\hline Farelo de Soja & 10,2 & 6,4 & 2,1 & 0,0 \\
\hline Calcário & 0,85 & 0,85 & 0,85 & 0,85 \\
\hline Premix & 0,425 & 0,425 & 0,425 & 0,425 \\
\hline Sal branco & 0,425 & 0,425 & 0,425 & 0,425 \\
\hline Total & 100,0 & 100,0 & 100,0 & 100,0 \\
\hline \multicolumn{5}{|c|}{ Composição química (\% na MS) } \\
\hline \multicolumn{5}{|c|}{ Variáveis } \\
\hline Matéria seca (MS) & 84,72 & 84,81 & 84,88 & 84,96 \\
\hline Materia orgânica (MO) & 93,97 & 94,11 & 94,23 & 94,35 \\
\hline Proteína bruta (PB) & 13,26 & 12,62 & 12,15 & 11,84 \\
\hline Extrato etéreo (EE) & 2,12 & 3,64 & 5,16 & 6,68 \\
\hline $\begin{array}{l}\text { Fibra em detergente } \\
\text { neutro (FDN) }\end{array}$ & 65,93 & 66,19 & 66,24 & 66,08 \\
\hline $\begin{array}{l}\text { Fibra em detergente } \\
\text { neutro (FDA) }\end{array}$ & 50,78 & 50,65 & 50,31 & 49,78 \\
\hline Matéria mineral (MM) & 6,01 & 5,87 & 5,75 & 5,63 \\
\hline $\begin{array}{l}\text { Carboidratos totais } \\
(\mathrm{CHT})\end{array}$ & 78,61 & 77,86 & 76,93 & 75,84 \\
\hline $\begin{array}{l}\text { Carboidratos } \\
\text { fibrosos (CNF) }\end{array}$ & 13,66 & 12,45 & 11,30 & 10,20 \\
\hline $\begin{array}{l}\text { Nutriente } \\
\text { totais (NDT) }{ }^{1}\end{array}$ & 65,12 & 65,97 & 66,88 & 67,84 \\
\hline
\end{tabular}


A conversão alimentar (CA) foi obtida por meio da média do consumo de MS dividido pelo ganho de peso médio diário de cada tourinho submetido às diferentes rações experimentais.

A determinação da eficiência alimentar (EA) foi calculada dividindo-se o ganho médio diário de cada tourinho pela consumo médio diário de MS.

O bagaço de cana-de-açúcar hidrolisado $e$ as sobras passaram primeiramente pelo processo de présecagem em estufa de ventilação forçada a $60^{\circ} \mathrm{C}$ por 72 horas até obtenção do peso constante. A determinação do teor de MS dos alimentos e das sobras foi realizada em estufa a $105^{\circ} \mathrm{C}$ (por aproximadamente 12 horas). O teor de nitrogênio dos alimentos estudados e das sobras foi obtido pelo método semi-micro-Kjeldahl, usando 6,25 como fator de conversão para $\mathrm{PB}$, a matéria mineral $(\mathrm{MM})$ e a matéria orgânica $(\mathrm{MO})$ foi realizada pelo método por incineração em mufla a $600^{\circ}$ $\mathrm{C}$ e o teor de EE foi determinado pela extração por lavagem com éter de petróleo, segundo citações de Silva e Queiroz (2002).

A determinação da fibra em detergente neutro (FDN) e fibra em detergente ácido (FDA) dos alimentos e das sobras foram realizadas de acordo com Van Soest et al. (1991).

A partir dos resultados das análises de proteína (PB), extrato etéreo (EE) e matéria mineral (MM) foi realizado o cálculo dos carboidratos totais (CHT), de acordo com a equação de Sniffen et al. (1992): $\mathrm{CHT}=100-$ $(\% \mathrm{~PB}+\% \mathrm{EE}+\% \mathrm{MM})$ e para os carboidratos não fibrosos (CNF) onde: $\mathrm{CNF}=\% \mathrm{CHT}-\% \mathrm{FDN}$. O valor de NDT dos alimentos foi obtido segundo citações de Valadares Filho et al. (2006a).

Foi utilizado um delineamento experimental inteiramente casualizado com quatro tratamentos com 8 repetições, para o ganho médio diário.
Para o consumo, conversão e eficiência alimentar foi utilizado o peso individual dos animais, porém o consumo médio foi avaliado por baia, pela limitação do número de baia.

A análise das variáveis estudadas (ganho médio diário, conversão e eficiência alimentar) foi interpretada por meio do programa Sistema de Análise Estatística e Genética - SAEG (UNIVERSIDADE FEDERAL DE VIÇOSA, 1997) através da análise de regressão considerando $5 \%$ de significância.

\section{RESULTADOS E DISCUSSÃO}

Os diferentes teores de inclusão do caroço de algodão $(0 \%, 10 \%, 20 \%$ e $30 \%$ na $M S)$ não influenciaram $(P>$ $0,05)$ o GMD, a CA e a EA, em rações contendo alto teor de concentrado $(85 \%)$ constituídas por co-produtos agroindustriais fornecidas à tourinhos confinados, conforme demonstrado na Tabela 3.

O presente estudo demonstrou que a inclusão de $30 \%$ de caroço de algodão em rações contendo a casca do grão de soja como fonte de pectina (concentrado) em rações formuladas com co-produtos agroindustriais fornecidas a tourinhos não alterou $(P>$ $0,05) \quad 0 \quad$ GMD. Este resultado provavelmente pode estar relacionado com a taxa de digestão dos alimentos utilizados em especial a casca do grão de soja rica em pectina (Zambom et al. 2008) que apresenta as maiores percentagens (73,1 a 53,7\%) na ração total.

Foi observado que os resultados do GMD de tourinhos alimentados com a inclusão do caroço de algodão não foram influenciados $(P>0,05)$ pela variação no teor de extrato etéreo (EE) das rações totais de 2,12 a $6,68 \%$ de EE para os diferentes teores de inclusão do caroço de algodão. 
Inclusão do caroço de algodão em rações de alto concentrado constituído de co-produtos agroindustriais sobre o desempenho animal em tourinhos confinados.

Tabela 3. Valores de consumo de matéria seca, proteína bruta e extrato etéreo, ganho médio diário, conversão alimentar e eficiência alimentar de tourinhos alimentados com os diferentes teores de inclusão do caroço de algodão

Variávei Teores de inclusão de caroço Regressã CV\%

s de algodão nas rações o

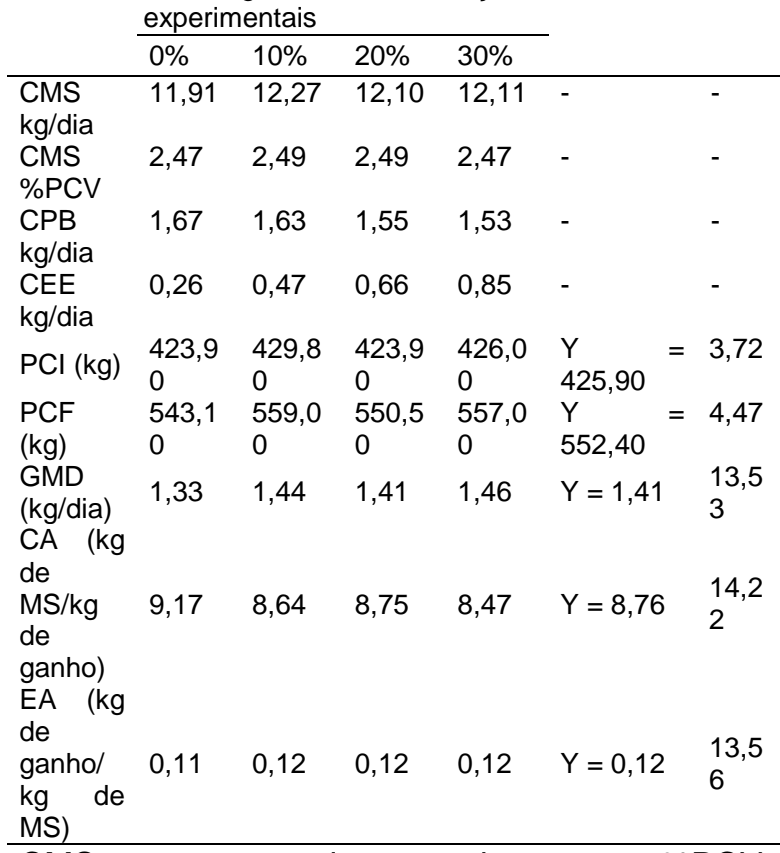

CMS: consumo de materia seca; \%PCV: percentaem do peso corporal vivo; CPB: consumo de proteina bruta; CEE: consumo de extrato etéreo; PCl: peso corporal inicial; PCF: peso corporal final; GMD: ganho médio diário; CA: conversão alimentar; EA: eficiencia alimentar e CV: coeficiente de variação;

Provavelmente a inclusão do caroço de algodão em até $30 \%$ nas rações constituídas por co-produtos agroindustriais fornecidas a tourinhos em confinamento não influenciou o GMD devido ao correto balanceamento dos nutrientes dietéticos, principalmente os carboidratos estruturais e extrato etéreo, que se encontram dentro das sugestões do NRC (1996), onde as dietas de ruminantes deverão apresentar no mínimo 29\% de FDN, a qual garante um ambiente favorável ao desenvolvimento dos microrganismos além do teor de $E E$, apresentar um teor máximo de $7 \%$ na dieta (NRC, 1996) para não alterar o ambiente ruminal e assim não reduzir o consumo, a digestibilidade dos alimentos (fibra) e conseqüentemente reduzir o GMD.
Estudo realizado por Teixeira e Borges (2005), para avaliar os diferentes níveis de inclusão $(0,12,24$, 35 e $49 \%$ ) de caroço de algodão sobre o consumo e digestibilidade da fração fibrosa do feno de braquíaria em ruminantes, demonstrou que os diferentes níveis de caroço de algodão propiciaram um teor de EE nas dietas variando de 1,25 a 9,00\%. Mesmo assim, os autores não observaram diferença $(P>0,05)$ para o consumo e coeficiente de digestibilidade da MS, FDN e FDA das diferentes rações contendo caroço de algodão.

Entretanto, estudo sobre a utilização do caroço de algodão como fonte de fibra e proteína em dietas a base de palma forrageira para vacas em lactação foi conduzido por Melo et al. (2005). Os autores observaram que 0 caroço de algodão influenciou $(P<0,05)$ o consumo e a digestibilidade aparente da $P B$ e $E E$, mas não interferiu $(P>$ $0,05)$ sobre $O$ coeficiente de digestibilidade dos demais nutrientes.

Normalmente a inclusão de fonte de gordura em rações de ruminantes pode proporcionar um efeito benéfico direto sobre o GMD, através do aumento da densidade energética das rações (Zinn e Plascencia, 1996), ou indireta através da redução da produção de metano no rúmen uma vez que a gordura não fornece substrato fermentável no rúmen na mesma proporção que os carboidratos de reserva e/ou os estruturais (Van Soest, 1994). Entretanto, os valores de NDT das rações contendo $0 \%, 10 \%, 20 \%$ e $30 \%$ de inclusão do caroço de algodão apresentaram valores semelhantes (Tabela 1). Desta maneira, ocorreu a substituição do carboidrato fermentável no rúmen proveniente da casca do grão de soja pela gordura de alta digestibilidade intestinal proveniente do caroço de algodão, a qual diminui a 
energia de fermentação ruminal. Provavelmente a substituição da fonte de energia através da adição de até $30 \%$ do caroço de algodão nas rações de tourinhos não alterou 0 funcionamento normal do rúmen propiciando um valor médio para o GMD de $1,41 \mathrm{~kg} /$ animal para os diferentes teores de inclusões do caroço de algodão.

Para a CA foi verificado uma variação de 9,17 a 8,47 kg de MS/kg de ganho, ou seja, aproximadamente $7,63 \%$ entre as rações contendo $30 \%$ de caroço de algodão em relação a ração com $0 \%$ de caroço de algodão. Provavelmente, o caroço de algodão propiciou um efeito associativo entre os ingredientes, o que pode ter refletido nesta variação sobre a CA dos tourinhos em confinamento.

A CA e GMD de novilhos alimentados com diferentes fonte de lipídeos foi avaliado por Aferri et al. (2005). Os autores não observaram diferença $(P>0,05)$ para o GMD e CA para os diferentes tratamentos constituídos por caroço de algodão ( $21 \%$ na dieta), $5 \%$ de sais de cálcio e ácidos graxos e tratamento controle sem adição de lipídeos.

O valor de CA de 8,38 kg de $\mathrm{MS} / \mathrm{kg}$ de ganho encontrado por Aferri et al. (2005) foi menor em relação ao encontrado no presente estudo para o nível de $20 \%$ de inclusão de caroço de algodão de $8,75 \mathrm{~kg}$ de MS/kg de ganho. Esta variação provavelmente foi devido às diferenças nos constituintes das rações existentes entre os estudos.

No entanto, a literatura demonstra que teores elevados de gorduras na dieta podem apresentar tendência em melhorar a conversão alimentar quando as dietas apresentarem teor de EE próximo a recomendação máxima do NRC (1996) de 7,0\% na dieta. Estudo realizado por Ngidi et al. (1990), para avaliar o efeito dos sais de cálcio e ácidos graxos na dieta de novilhos sobre 0 desempenho animal, demonstrou uma tendência de melhora na conversão alimentar para novilhos alimentados com dietas contendo acima de $6,0 \%$ EE $(8,03 \mathrm{~kg}$ de $\mathrm{MS} / \mathrm{kg}$ de ganho) em relação aos novilhos alimentados com dietas contendo 2,0\% de $E E(9,43 \mathrm{~kg}$ de $M S / \mathrm{kg}$ de ganho).

Os valores de EA variaram de 0,11 a $0,12 \mathrm{~kg}$ de ganho/kg de MS, para os diferentes teores de inclusão do caroço de algodão na dieta. Estes valores de EA ficaram abaixo do encontrado por Pesce (2008), o qual avaliou o efeito da dieta contendo caroço de algodão $(0,10$ e $20 \%$ ) sobre o desempenho, características quantitativas da carcaça e qualitativas da carne de novilhos nelores confinados. $\mathrm{O}$ autor observou um efeito crescente $(P<0,05)$ no valor de EA para a inclusão de até $20 \%$ de caroço de algodão na dieta de novilhos confinados com uma variação de 0,12 a $0,15 \mathrm{~kg}$ de ganho/kg de MS.

Os valores de EA do presente estudo podem auxiliar na compreensão dos dados obtidos para o GMD, uma vez que os valores próximos de consumo de MS e EA para os diferentes teores de inclusão de caroço de algodão juntamente com as características da composição químicas dos alimentos que compuseram as rações, podem ter melhorado o ambiente ruminal, mantido a taxa de passagem constante o que propiciou eficiência de conversão e ganho constante com a inclusão do caroço de algodão nas rações com alto concentrado para tourinhos terminados em confinamento.

\section{CONCLUSÃO}

Conclui-se que pode ser fornecido até $30 \%$ na MS da dieta de caroço de algodão em rações compostas com alto concentrado (casca do grão de soja e farelo de soja) a tourinhos terminados 
22

ııılusão do caroço de algodão em rações de alto concentrado constituído de co-produtos agroindustriais sobre o desempenho animal em tourinhos confinados.

em confinamento sem influenciar o ganho médio diário a conversão alimentar e a eficiência alimentar.

\section{AGRADECIMENTOS}

Ao Conselho Nacional de Desenvolvimento Cientifico e Tecnológico (CNPq) por ter financiado a execução do presente estudo. A Fundação de Amparo à Pesquisa do Estado de Mato Grosso (FAPEMAT) por ter concedido bolsas de iniciação cientifica aos acadêmicos do Curso de Zootecnia para auxiliarem 0 desenvolvimento do estudo. Ao senhor Paulo Cárdia proprietário da fazenda Lagoa do Guaporé por ter apoiado e auxiliado no desenvolvimento da pesquisa cedendo às instalações $e$ mão-de-obra da fazenda. A empresa Suprema Nutrição Animal, por ter confeccionado os concentrados utilizados no estudo.

\section{REFERÊNCIAS}

AFERRI, G.; LEME, P.R.; SILVA, S.L.; PUTRINO, S.M. et al. Desempenho e características de carcaça de novilhos alimentados com dietas contendo diferentes fontes de lipídeos. Revista Brasileira de Zootecnia, v.34, n.5, p.1651-1658, 2005.

ANUALPEC 2007. Anuário da pecuária brasileira. São Paulo: FNP Consultoria e Comércio, 2007. 368p.

AZEVEDO, P.S. A casca do grão de soja em substituição ao feno de gramíneas nas rações com diferentes fontes protéicas para bovinos. Jaboticabal: Universidade Estadual Paulista, 1998. 53p. Tese (Doutorado em Zootecnia) - Universidade Estadual Paulista, 1998.

BULLE, M.L.M.; RIBEIRO, F.G.; LEME, P.R. Uso do bagaço de cana-de-açúcar como único volumoso em dietas de alto teor de concentrado. 1. Desempenho. In: REUNIÃO ANUAL DA SOCIEDADE BRASILEIRA DE ZOOTECNIA,
36., 1999, Porto Alegre. Anais... Porto Alegre: Sociedade Brasileira de Zootecnia, (1999). CDROM. Nutrição de Ruminantes. Confinamento e bovinos de corte.

COPPOCK, C.E.; LANHAM, J.K.; HORNER, J.L. $A$ review of nutritive value and utilization of whole cottonseed, cottonseed meal and associated by-products by dairy cattle. Animal Feed Science and Technology, v.18, n.2, p.89129, 1987.

EZEQUIEL, J.M.B. Uso de caroço de algodão na alimentação animal. In: SIMPÓSIO GOIANO SOBRE MANEJO E NUTRIÇÃO DE BOVINOS, 3., 2001, Goiânia. Anais... Goiânia: Colegio Brasileiro de Nutrição Animal, 2001. p.307328.

FERNANDES, J.J.R.; PIRES, A.V.; SANTOS, F.A.P. et al. Teores de caroço de algodão em dietas contendo silagem de milho para vacas em lactação. Acta Scientiarum Animal Sciences, v.24, n.4, p.1071-1077. 2002.

GOMES, I.P.O. Substituição do milho pela casca de soja em dietas com diferentes proporções de volumoso:concentrado para bovinos em confinamento. Jaboticabal: Universidade Estadual Paulista, 1998. 84p. Tese (Doutorado em Zootecnia) - Universidade Estadual Paulista, 1998.

HARVATINE, D.I. et al. Whole linted cottonseed as a forage substitute: fiber effectiveness and digestion kinetics. Journal of Dairy Science, v.85, p.1988-1999, 2002.

HENRIQUE, W.; LEME, P.R.; LANNA, D.P.D. Avaliação do milho úmido com bagaço de cana ou silagem de milho na engorda de bovinos. 1. Desempenho animal e características da carcaça. In: REUNIÃO ANUAL DA SOCIEDADE BRASILEIRA DE ZOOTECNIA, 36., 1999, Porto Alegre. Anais... Porto Alegre: Sociedade Brasileira de Zootecnia, [1999]. CD-ROM. Nutrição de Ruminantes. Confinamento e bovinos de corte.

HOOVER, W.H.; STOKES, S.R. Balancing carbohydrates and protein for optimum rúmen microbial yield. Journal of Dairy Science, v.74, n.10, p.3360-3371, 1991. 
LUDDEN, P.A.; CECAVA, M.J.; HENDRIX, K.S. The value of soybean hulls as a replacement for corn in beef cattle diets formulated with or without added fat. Journal of Animal Science, v.73, p.2706-2711, 1995.

MORAIS, J.B.; SUSIN, I.; PIRES, A.V. Substituição do feno de "coastcross" (Cynodon sp.) por casca de soja na alimentação de borregas confinadas. Ciência Rural, v.37, n.4, p.1073-1078, 2007.

MELO,A.A.S.; FERREIRA, M.A.; VERÁS, A.S.C. et al. Caroço de algodão como fonte de fibra e proteína em dietas a base de palma forrageira para vacas em lactação:digestibilidade. Acta Scientiarum, Animal Science, v.27, n.3, p.355362, 2005.

NGIDI, M.E.; LOERCH, S.C.; FLUHARTY, F.L. et al. effects of calcium soaps of long-chain fatty acids on feedlot performance, carcass characteristics and ruminal metabolism of steers. Journal of Animal Science. v.26, p.2555-2564, 1990.

NATIONAL RESARCH COUNCIL - NRC. Nutrient requirements of dairy cattle. $6 \mathrm{ed}$. Washington: Natonal Academy Press, 1989.

NATIONAL RESARCH COUNCIL - NRC. Nutrient requirements of dairy cattle. $7 \mathrm{ed}$. Washington: Natonal Academy Press, 1996.

OLIVEIRA, M D S.; ANDRADE, A.T.; BARBOSA, J.C. et al. Digestibilidade da canade-açúcar hidrolisada, in natura e ensilada para bovinos. Ciência Animal Brasileira, v.8, n.1, p.41-40, 2007.

PERUCHENA, C.O. Suplementación de bovinos para carne sobre pasturas tropicales, aspectos nutricionales, productivos y economicos. In: REUNIÃO ANUAL DA SOCIEDADE BRASILEIRA DE ZOOTECNIA, 36., 1999, Porto Alegre. Palestras... São Paulo: SBZ/Gmosis, [1999] 17par. CDROM.

PESCE, D.M.C. Efeito da dieta contendo caroço de algodão no desempenho, característica quantitativa de carcaça e qualitativa da carne de novilhos Nelore confinados. 2008, Pirassununga. 155f. Tese (doutorado em Zootecnia). Curso de Pós-Graduação em Zootecnia. Universidade de São Paulo - USP.

RESENDE, K.T.; PEREIRA FILHO, J.M.; TRINDADE, I.A.C.M. Exigências nutricionais de caprinos leiteiros. In: REUNIÃO ANUAL DA SOCIEDADE BRASILEIRA DE ZOOTECNIA, 38, 2001, Piracicaba. A produção animal na visão dos brasileiros / Editado por Wilson Roberto Soares Mattos, et al. - Piracicaba: FEALQ, 2001. p. 484-496.

RESTLE, J.; FATURI, C.; FILHO, D.C.A. BRONDANIS, I.L. et al. Substituição do grão de sorgo por casca de soja na dieta de novilhos terminados em confinamento, Revista Brasileira de Zootecnia, v.33, n.4, p.10091015, 2004.

ROGÉRIO, M.C.P. et al. Uso do carozo de algodão na alimentação de ruminantes. Arquivo de Ciência Veterinária e Zoologia - UNIPAR, v.6, n.1, p.85-90, 2003.

SANTELLO, G.A.; MACEDO, F.AF.; MEXIA, A.G. et al. Características de carcaça e análise do custo de sistemas de produção de cordeiras $1 / 2$ Dorset Santa Inês. Revista Brasileira de Zootecnia, v.35, n.4, supl., p.1009-1015, 2006.

SILVA, D.J.; QUEIROZ. A.C. Análise de alimentos (Métodos químicos e biológicos). 2a ed., Viçosa, MG: UFV. 2002, 178p.

SNIFFEN, C.J.; O'CONNOR, J.D.; Van SOEST, P.J. A net carbohydrate and protein system for evaluating cattle diets: II. Carbohydrate and protein availability. Journal of Animal Science, v.70, n.10, p.3562-3577, 1992.

TAMBARA, A.A.C.; OLIVO, C.J.; PIRES, M.B.G. Avaliação in vivo da digestibilidade da casca do grão de soja moída com ovinos. Ciência Rural, v.25, n.2, p.283-287, 1995.

TEIXEIRA, J.C. Nutrição de ruminantes. Lavras: Ufla, 1998. 
Inclusão do caroço de algodão em rações de alto concentrado constituído de co-produtos agroindustriais sobre o desempenho animal em tourinhos confinados.

24 EIRA, D.A.B.; BORGES, I. Efeito do nivel de caroço integral de algodão sobre o consumo e digestibilidade aparente da fração fibrosa do feno de braquíaria (Brachiaria decumbens) em ovinos. Arquivo Brasileiro de Medicina Veterinária e Zootecnia, v.57, n.2, p.229-233, 2005

UNIVERSIDADE FEDERAL DE VIÇOSA - UFV. Sistema de análises estatísticas e genéticas SAEG. Viçosa: UFV. 150p. 1997. (Manual do usuário).

VALADARES FILHO, S.C.; MAGALHÃES , K.A.; ROCHA JÚNIOR, V.R. et al. Tabelas brasileiras de composição de alimentos para bovinos. 2 ed. Viçosa: UFV, 2006a, 329p.

VALADARES FILHO, S.C.; PAULINO, P.V.R.; MAGALÃES, K.A. Exigências nutricionais de zebuínos e tabelas de composição de alimentos BR-corte. 1. ed. Viçosa: UFV, 2006b, 142p.

VAN SOEST, P.J.; ROBERTSON, J.B.; LEWIS, B.A. Methods for dietary fiber neutral detergent fiber, and nostarch polysaccharides in relation to animal nutrition. Journal of Dairy Science, v.74, n.12, p.3583-3597, 1991.

VAN SOEST, P.J. Nutritional ecology of the ruminant. 2 ed., London: Constock Publishing Associates. 1994. 476p.

ZAMBOM, M.A.; SANTOS, G.T.; MODESTO, E.C. Valor nutricional da casca do grão de soja, farelo de soja, milho moído e farelo de trigo para bovinos. Acta Scientiarum Animal Sciences, v.23, n.4, p.937-943, 2001.

ZAMBOM, M.A.; ALCALDE, C.R.; HASHIMOTO, J.H. et al. Parâmetros digestivos, produção e qualidade do leite de cabras Saanen recebendo rações com casca do grão de soja em substituição ao milho. Acta Scientiarum Animal Sciences, v.29, n.3, p.309-316, 2007.

ZAMBOM, M.A.; ALCALDE, C.R.; SILVA, K.T. et al. Desempenhoe digestibilidade dos nutrientes de rações com casca do grão de soja em substituição ao milho para cabras Saanen em lactação e no pré-parto. Revista Brasileira de Zootecnia, v.37, n.7, p.1311-1318, 2008.
ZINN, R.A.; PLASCENCIA, A. Effects of forage level on the comparative feeding value of supplemental fat in growing-finishing diets for feedlot cattle. Journal of Animal Science, v.74, p.1194-1201, 1996. 